\title{
A Simplified Calculation Method for the Near-Slope Laterally Loaded Pile Based on a Passive Wedge Model
}

\author{
Minghui Yang, ${ }^{1}$ Bo Deng $\mathbb{D}^{2}{ }^{2}$ and Yuhui Wang ${ }^{2}$ \\ ${ }^{1}$ Associate Professor, College of Civil Engineering, Hunan University, Changsha 410082, Hunan Province, China \\ ${ }^{2}$ Ph.D. Candidate, College of Civil Engineering, Hunan University, Changsha 410082, Hunan Province, China
}

Correspondence should be addressed to Bo Deng; parl_d@126.com

Received 29 April 2019; Accepted 13 June 2019; Published 1 July 2019

Academic Editor: Jian Ji

Copyright (C) 2019 Minghui Yang et al. This is an open access article distributed under the Creative Commons Attribution License, which permits unrestricted use, distribution, and reproduction in any medium, provided the original work is properly cited.

When a pile is placed near the slope, the lateral loading capacity of the pile decreases significantly due to the weakening effect of soil resistance near the slope. As such, a modified soil passive wedge model for near-slope laterally loaded piles is presented to consider the weakening effect in this paper. According to development depth of different wedges, the shapes of soil passive wedge can be classified into three sorts, so as to fully analyze the influence of the slope shape and the distance from the pile center to the slope crest. On this basis, a concept of equivalent depth is proposed considering the differences of laterally loaded piles near the slope and in the horizontal ground. Besides, the unit ultimate soil resistance, which can be obtained along the different depths of pile, is introduced into the $\mathrm{p}-\mathrm{y}$ curve of the soil, for achieving solution methods of internal force and displacement of laterally loaded piles under the slope weakening effect. The results of laboratory model and field tests on laterally loaded piles are compared with the proposed method, demonstrating its validity and accuracy. Furthermore, the influence of the near-slope distance on the loading capacity of the pile is fully analyzed in detail, indicating the critical near-slope distance is increasing with the increase of the undrained strength, while independent of the slope angle.

\section{Introduction}

Laterally loaded piles generally refer to common piles which are subjected to lateral loads caused by wind, earthquake, or passive lateral pressure caused by soil movement. Recently, more and more laterally loaded piles are constructed near a natural or constructed slope, such as bridge abutments adjacent to approach embankments [1], built piles for slope stabilization $[2,3]$, and existing piles adjacent to excavation $[4,5]$. In these cases, in light of the weaken lateral soil resistance near the slope, the lateral loading capacity of piles decreases obviously compared with that constructed in horizontal ground [6-8]. Therefore, it is critical to consider the influence of slope for estimating the safety of piles constructed near the slope accurately.

Load-transfer curve method is commonly used for analyzing piles under lateral loads, known as p-y curve method, in which the soil or rock is represented as a series of independent springs and the pile as an Euler-Bernoulli beam.
The shape of p-y curves is largely affected by properties of the pile and the soil around the pile. Conventional p-y models are typically applicable to piles installed in horizontal ground [9-12]. Complex studies also have been carried out based on experimental and numerical investigations of piles installed in sloping ground. Poulos [6] conducted smallscale laboratory tests on piles near a slope or cut to study the effects of loading direction and near-cut distance on lateral response of piles. Chae et al. [13] performed several numerical studies with a 3D finite element model test and prototype test on laterally loaded single piles and pile groups in homogeneous sand with $30^{\circ}$ slope. Muthukkumaran et al. [14] carried out model tests on sandy soil under surcharge loading and developed nondimensional $p-y$ curves for piles on sloping ground by including a reduction factor using the experimental results. Georgiadis and Georgiadis $[15,16]$ performed 3D Finite Element analyses to study the behavior of piles near the slope under lateral loading conditions. The study proposed a new p-y criterion for piles near clay slope 
and found that below a critical depth which increases with the increase of the pile to slope crest, the presence of the slope affects the distribution of ultimate lateral pile load $p_{\mathrm{u}}$. Based on the model tests in cohesionless soil, Muthukkumaran [17] found that when the pile is located at a distance of more than 15 times the pile diameter from the slope ground, the existence of the slope has a negligible effect on the bearing capacity of the pile. Nimityongskul et al. $[18,19]$ reported full-scale test results for piles near a clay slope, which show that the effect of the slope is significantly reduced at a distance of 4 times the pile diameter and fully disappears at 8 times the pile diameter. Rathod et al. [20] investigated the effect of slope on p-y curves due to static lateral loading in soft clay and presented a new $p-y$ curve on a basis of the experimental results.

However, analyzing the soil failure model around the pile is a more convenient way to obtain the expression of $\mathrm{p}-\mathrm{y}$ curves from a theoretical point of view. Murff and Hamilton [21] proposed an improved passive wedge model to describe the failure mode of soil around piles, which can consider the parameters of strength nonhomogeneity, soil-pile adhesion, and suction on the back of the pile. Based on this model, an empirical equation was also given for predicting the ultimate load of piles using the upper bound theorem. Reese et al. [22] presented a passive wedge model for soil around the pile subjected to lateral loads. Kim et al. [12] developed a new hyperbolic p-y curve with an improved wedge model for representing a pile-soil interaction for laterally loaded piles in the ground. Similarly, Lin et al. $[23,24]$ proposed a simplified method for the analysis of laterally loaded piles in sand and clay under a scour condition based on a failure wedge model. Nevertheless, limited studies have been conducted to study the soil failure model around piles near a slope and the corresponding ultimate soil resistance characteristics.

For this purpose, this study focuses on developing a new soil passive wedge model around the laterally loaded pile installed and near a slope and gives a new formula to computer the ultimate resistance of the wedge of soil. Several forms of soil failure wedge are presented to consider the effect of the slope configuration and the distance from the pile center to the slope crest. On this basis, conventional p-y curves are modified to involve the slope effect and pile behavior. Furthermore, a new method for defining the critical near-slope distance is proposed based on the distribution law of the ultimate soil resistance around the pile, and the determination of critical distance from the pile center to slope crest as well as its influence factors are fully discussed. Compared with the previous method, this calculation mode can take the influence of soil parameters into account and can derive the critical near-slope distance through theoretical analysis.

\section{Passive Wedge Mechanical Model of Laterally Loaded Pile}

2.1. Ultimate Soil Resistance Model around the Pile in the Ground. When subjected to pile loading, lateral passive extrusion would occur in shallow soil around the pile; thus, the shear failure surface of the soil is extended to the ground and forming the soil passive failure wedge model. Generally, the ultimate resistance of soils is related to the lowest value of two possible failure mechanisms: a wedge failure mechanism at shallow depths and a flow failure around the pile at greater depths $[10,22]$. This dual approach can be implemented in most of the proposed p-y curves $[9,10,25]$. Moreover, the passive wedge develops along the depth with increase of load to form a larger wedge failure body, as shown in Figure 1. For the wedge failure mechanism at shallow depth, Reese et al. [22] proposed a simplified three-dimensional model (Figure 2) to give some insight into the variation of the ultimate lateral resistance with depth. It can be seen that the characteristics of the wedge are mainly determined by three parameters: the depth of $z$, the angle $\beta$ between the sliding surface and the vertical plane, and the thickness of $D$. Besides, $\beta$ is suggested to be $45^{\circ}$ by Reese et al. [22] for reflecting passive failure modes under undrained conditions. In this regard, similar assumption is adopted in the analysis of this paper, and the sliding block can be simplified as a threedimensional straight soil wedge.

As shown in Figure 2, a three-dimensional soil wedge is used for force-balance analysis. $D$ is the thickness of threedimensional soil wedge, which equals the diameter of the pile. $F_{\mathrm{u}}$ is the lateral soil resistance around the pile, $F_{\mathrm{t}}$ and $F_{\mathrm{s}}$ are shear forces acting on the side plane and bottom plane of the wedge, $F_{\mathrm{f}}$ is the vertical friction force of the pile, $F_{\mathrm{n}}$ is the vertical force acting on the side of the wedge, and $W$ is the weight of the wedge. According to the force-balance equation of the wedge, it is easy to derive that

$$
\begin{aligned}
& F_{\mathrm{u}}=\frac{2 F_{\mathrm{t}}+W \cos \beta+F_{\mathrm{S}}}{\sin \beta}, \\
& F_{\mathrm{s}}=\frac{C_{\mathrm{u}} D z}{\cos \beta}, \\
& F_{\mathrm{t}}=\frac{\tan \beta C_{\mathrm{u}} z^{2}}{2}, \\
& W=\frac{\tan \beta D \gamma^{\prime} z^{2}}{2},
\end{aligned}
$$

where $\gamma^{\prime}$ is the average effective gravity from ground to depth $z$, and $C_{\mathrm{u}}$ is the average undrained shear strength from ground to depth $z$. By substituting equations (2)-(4) in equation (1), the ultimate resistance of the wedge of soil at a depth of $z$ can be obtained as

$$
F_{\mathrm{u}}=\frac{1}{2} \gamma^{\prime} D z^{2}+2 C_{\mathrm{u}} D z+\sqrt{2} C_{\mathrm{u}} z^{2} .
$$

\subsection{Passive Wedge Model for Near-Slope Laterally Loaded} Piles. For near-slope laterally loaded piles, the existence of the slope weakens the ultimate resistance of the soil surrounding the pile. The degree of weakening is not only related to the geometric shape of the slope, but also to the distance between slope crest and piles. As shown in Figure 3(a), for the laterally loaded pile in sloping ground, 


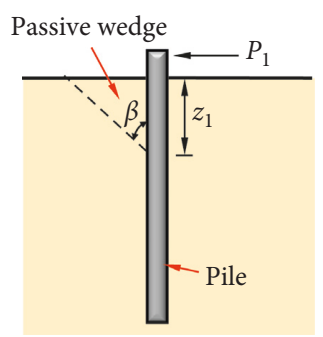

(a)

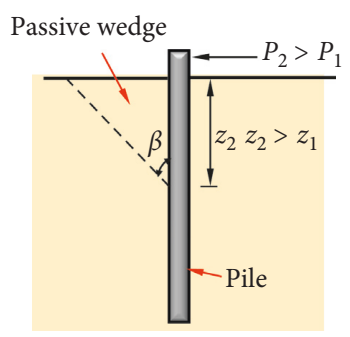

(b)

Figure 1: Laterally loaded pile in horizontal ground with different loading: (a) $P_{1}$; (b) $P_{2}$.

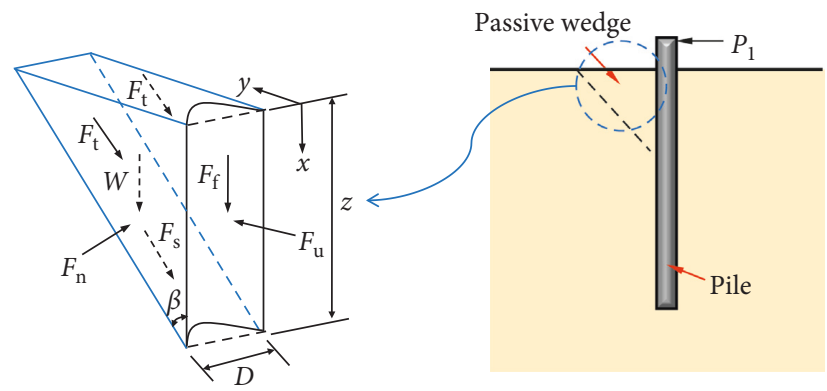

FIgURE 2: Mechanical analysis of passive soil wedge.

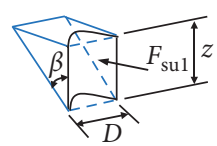

(1) $0<z<H_{1}$

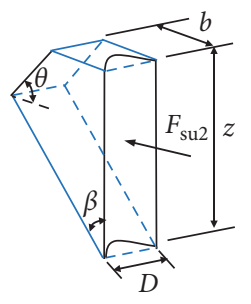

(2) $H_{1}<z<H_{2}$

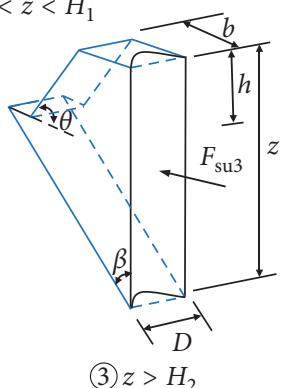

(3) $z>\mathrm{H}_{2}$

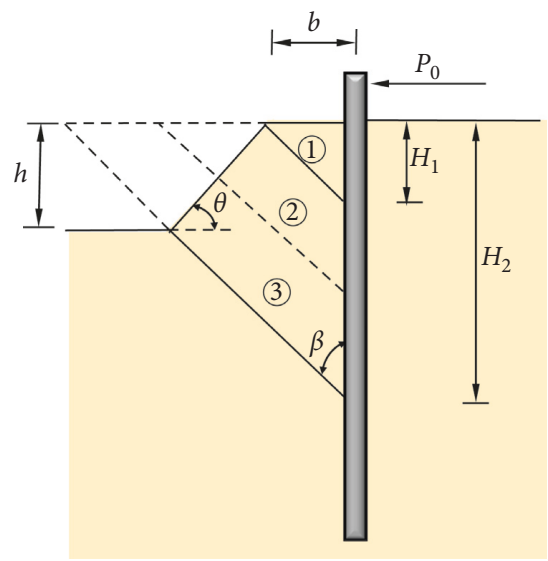

FIgURE 3: Wedge failure model for a laterally loaded pile near a slope. the distance from the slope crest is $b$, the slope height is $h$, and the angle between them is $\theta$.

To assess the effect of a slope near the pile, the wedge failure mode needs to be modified to account for slope characteristics. It is assumed that for laterally loaded piles installed near the slope, the failure model of the soil around the pile is still similar to that in horizontal ground, namely, passive soil wedges failure: (1) the soil still has a wedge failure model near a slope; (2) the shape of the wedge gradually extends to the deeper depth as the load increases; (3) the angle between the failure surface and the vertical plane is still $\beta$. These assumptions have been adopted by Stewart [26]. It should be noted that natural soils have significant spatial variability [27] and many reliability methods have been proposed $[28,29]$, but this paper assumes that the slope soil is homogeneous for simplifying the calculation.

However, the shape of the near-slope failure wedge is affected by slope characteristics. According to the different depth of extension, it can be analyzed in three cases, as shown in Figure 3, where $H_{1}=b, H_{2}=b+h(1+\tan \theta)$.

(1) If $0<z \leq H_{1}$, the load is small, and the surface of failure wedge extends to the ground and does not intersect with the slope. The wedge shape is similar to that of the laterally loaded pile in horizontal ground, namely, the three-dimensional straight wedge. Now the lateral resistance provided by the soil wedge is $F_{\text {su1 }}$. 
(2) If $H_{1}<z<H_{2}$, with the increase of lateral load, the failure surface of the wedge extends upwardly to an intersection with the slope. The shape of the failure wedge is partial deletion compared to that in horizontal ground. Now the lateral resistance provided by the wedge is $F_{\text {su2 }}$.

(3) If $z \geq H_{2}$, the corresponding slope height $h$ is small and less than the embedded depth of the pile. Now the surface of failure wedge intersects the slope bottom, and the lateral resistance provided by the wedge is $F_{\text {su3 }}$.

$F_{\text {su1 }}, F_{\text {su2 } 2}$, and $F_{\text {su3 }}$ in equations (6)-(8) are obtained based on the force equilibrium of the wedge at failure. The calculation of $F_{\text {sul }}$ is similar to equation (5) for the laterally loaded pile in ground face. $F_{\text {su2 }}$ is the result of the vertical and horizontal force equilibriums of the wedge with the failure plane intersecting with the slope face. $F_{\text {su3 }}$ is the result of the vertical and horizontal force equilibriums of the wedge with the failure plane intersecting with the bottom of slope face.

$$
\begin{aligned}
F_{\text {sul }}= & \frac{1}{2} \gamma^{\prime} D z^{2}+2 C_{\mathrm{u}} D z+\sqrt{2} C_{\mathrm{u}} z^{2}, \\
F_{\mathrm{su} 2}= & \frac{\gamma^{\prime} D}{2}\left[\frac{(z+b \tan \theta)^{2}}{1+\tan \theta}-b^{2} \tan \theta\right]+\frac{2 C_{\mathrm{u}} D(z+b \tan \theta)}{1+\tan \theta} \\
& +\sqrt{2} C_{\mathrm{u}}\left[\frac{(z+b \tan \theta)^{2}}{1+\tan \theta}-b^{2} \tan \theta\right],
\end{aligned}
$$

$$
\begin{aligned}
F_{\text {su3 }}= & \frac{\gamma^{\prime} D}{2}\left[(z-h)^{2}+2 b h+h^{2} \cot \theta\right]+2 C_{\mathrm{u}} D(z-h) \\
& +\sqrt{2} C_{\mathrm{u}}\left[(z-h)^{2}+2 b h+h^{2} \cot \theta\right] .
\end{aligned}
$$

It can be seen from the formula above that when the pile adjacent to the slope is deflected laterally, the wedge failure mode of the shallow soil can be divided into three stages. Furthermore, when the deflection of the pile top is small, namely, a small load pile is applied to pile, the expression of the ultimate resistance $F_{\text {sul }}$ of soil around the pile near-slope crest is the same as that around the pile in the ground, indicating that the presence of the slope does not affect the ultimate resistance of the soil. That is reason why the loaddisplacement curves of the pile near-slope crest and that of the pile in the ground are almost coincident. Similar phenomena have been observed by Georgiadis and Georgiadis [16] and Nimityongskul et al. [19].

However, with the increase of pile top deflection, the existence of slope begins to affect the development of the failure wedge. Comparing with the pile constructed in the ground, it can be seen that the expression of $F_{\text {su2 }}$ for the pile built near-slope crest includes additional two parameters, slope angle $\theta$ and the near-slope distance $b$. It should be noted that previous studies have not considered the influence of slope height $h$ on the bearing capacity of piles $[16,19,20,30]$. When the slope height $h$ is smaller than the maximum depth of the failure wedge development, it is clear that $h$ will affect the ultimate resistance $F_{\text {su3 }}$, as shown in equation (8). Let $h$ be equal to 0 or let $\theta$ be equal to 0 , and $F_{\text {su2 }}$ or $F_{\text {su3 }}$ will degenerate into $F_{\mathrm{u}}$ for the case of pile in the ground, indicating that the theoretical derivation process of this paper is reasonable.

\section{Analytical Formulation}

3.1. BriefDescription of the Matlockp-y Curve. The p-y curves summarized herein were proposed by Matlock [9] for shortterm static lateral loading of piles in soft clay and are formulated as follows:

$$
\frac{p}{p_{\mathrm{u}}}=0.5\left(\frac{y}{y_{50}}\right)^{1 / 3} .
$$

In equation (9), $y_{50}$ is lateral displacement at half the maximum soil stress and can be determined by equation (10), and $p_{\mathrm{u}}$ is ultimate soil resistance per length, which is equal to the smaller value of $p_{\mathrm{u} 1}$ and $p_{\mathrm{u} 2}$ calculated in equation (11). When $y$ is greater than $8 y_{50}, p$ is equal to a constant value of $p_{\mathrm{u}}$ :

$$
\begin{gathered}
y_{50}=2.5 \varepsilon_{50} D, \\
\left\{\begin{array}{l}
p_{\mathrm{u} 1}=\left(3+\frac{\gamma^{\prime}}{C_{\mathrm{u}}} z+\frac{J z}{D}\right) C_{\mathrm{u}} D, \\
p_{\mathrm{u} 2}=9 C_{\mathrm{u}} D .
\end{array}\right.
\end{gathered}
$$

In equations (10) and (11), $\varepsilon_{50}$ is the strain at one-half of the maximum stress, $D$ is the pile diameter, $p_{\mathrm{u} 1}$ is the ultimate soil resistance per length near the ground surface, $p_{\mathrm{u} 2}$ is the ultimate soil resistance per length at depths, $\gamma^{\prime}$ is the effective unit weight of the soil, $J$ is a constant value (typically using 0.5), $z$ is the depth below the ground face, and $C_{\mathrm{u}}$ is the undrained shear strength of the soft clay.

3.2. Derivation of the Analytical Method. The analytical method is developed by establishing an imaginary equivalent wedge failure model in horizontal ground (the right part of Figure 4), which has the same ultimate soil resistance as the wedge failure model near the slope (the left part of Figure 4). The equivalent wedge is mainly characterized by the equivalent soil depth, $z^{\prime}$. The value of $z^{\prime}$ is back-calculated from the ultimate soil resistance which is quantitatively equal to the one computed from the wedge considering the slope. The analytical method is then developed by substituting $z$ in equation (11) with $z^{\prime}$ to modify the Matlock p-y curves.

The relationship between the equivalent depth $z$ of laterally loaded piles near a slope and that of $z^{\prime}$ in horizontal ground can be expressed as

$$
z^{\prime}=\frac{\sqrt{4 C_{\mathrm{u}}^{2} D^{2}+2 \gamma^{\prime} D+4 \sqrt{2} C_{\mathrm{u}} F_{\mathrm{su}}}-2 C_{\mathrm{u}} D}{\gamma^{\prime} D+2 \sqrt{2} C_{\mathrm{u}}} .
$$

In terms of three distinct extended patterns of soil wedge, $F_{\text {su }}$ represents $F_{\text {su1 }}, F_{\text {su2 }}$, and $F_{\text {su3 }}$, respectively. 


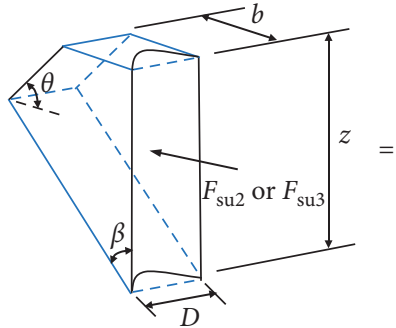

(a)

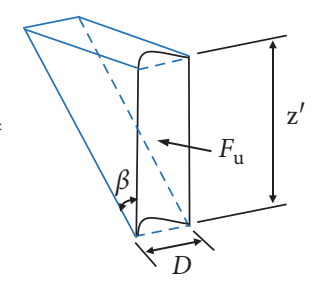

(b)

FIgURE 4: (a) The failure wedge modeled near the slope and (b) the equivalent failure wedge in horizontal ground.

Consequently, the ultimate resistance per length of soil around the pile near the slope crest can be expressed as

$$
\left\{\begin{array}{l}
p_{\text {su1 }}=\left(3+\frac{\gamma^{\prime}}{C_{\mathrm{u}}} z^{\prime}+\frac{J z^{\prime}}{D}\right) C_{\mathrm{u}} D, \\
p_{\mathrm{su} 2}=9 C_{\mathrm{u}} D .
\end{array}\right.
$$

From the formulas above, it can be seen that in the shallow soil where the wedge is damaged around the pile, the equivalent wedge depth is used to correct its ultimate resistance per length, so that the effect of slope on the shape of $\mathrm{p}-\mathrm{y}$ curve at depth $z$ can be fully considered, which in turn affects the final calculated internal force and displacement of the pile.

After obtaining the modified p-y curve of pile near a slope along the depth, horizontal displacement, bending moment and rotation angle along the pile can be calculated by the finite difference method using MATLAB code. Details flow chart can be found in Jiang et al. [7] and Yin et al. [8].

\section{Example Verification}

4.1. Comparison with Field Test 1. The validity of the simplified method is tested by comparing the results from the present approach with the field-measured results conducted by Nimityongskul et al. [19]. The slope angle $\theta$ is $26.6^{\circ}$, and the slope height $h$ is $2.73 \mathrm{~m}$. The distance $b$ from test pile to the slope crest is $0 D, 2 D, 4 D$, and $8 D$, respectively. The pile is made of steel. The cross section is round with the bending rigidity of $E_{p} I_{p}$ equal to $34875 \mathrm{kN} \cdot \mathrm{m}^{2}$ and the outer diameter $D$ equal to $0.324 \mathrm{~m}$. The length and the embedded depth of pile are $8.83 \mathrm{~m}$ and $7.92 \mathrm{~m}$, respectively. The soil unit weight $\gamma^{\prime}$ is $18.4 \mathrm{kN} / \mathrm{m}^{3}$, and the average undrained shear strength $C_{\mathrm{u}}$ is $76.6 \mathrm{kPa}$.

Figures 5(a)-5(d) depict the predicted and measured load-deflection curves. From the results, it can be seen that the proposed method can predict the load-pile head deflection of the laterally loaded piles near slopes in different near-slope distance. In general, the error of the proposed method and Georgiadis and Georgiadis [16] criterion estimate the pile head load within approximately 15\%. By contrast, the proposed method can predict slightly better than Georgiadis criterion, especially for large pile displacements.

Furthermore, in Figures 6(a) and 6(b), the predicted and measured load versus maximum bending moment curves in different near-slope distance are plotted. As compared to experimental data, the error in estimating the maximum moment of pile near slop crest with the distance of $0 D, 2 D, 4 D$, and $8 D$ is within approximately $10 \%$ by using the proposed method, which shows that the simplified method is reasonable in estimating the pile response.

4.2. Comparison with Field Test 2. Example 2 is the single pile test on the hard clay slope conducted by Buhushan [31]. Basic test parameters are as follows: the pile length is $5.185 \mathrm{~m}$, the pile diameter $D$ is $1.22 \mathrm{~m}$, the flexural rigidity $E_{p} I_{p}$ is $225000 \mathrm{kN} \cdot \mathrm{m}^{2}$, the slope angle $\theta$ is $20^{\circ}$, the undrained shear strength $C_{\mathrm{u}}$ is $220 \mathrm{kPa}, \varepsilon_{50}$ is 0.009 , and the soil unit weight $\gamma^{\prime}$ is $18.8 \mathrm{kN} / \mathrm{m}^{3}$. Figure 7 shows the results of comparison between the proposed method, field tests conducted by Bhushan [31], load-displacement curves by Georgiadis and Georgiadis [15], and the simplified method by Reese and Welch [10]. It can be observed that, in the case of small displacement, the proposed method agrees well with the experimental data when compared with load-displacement curves by Georgiadis and Georgiadis [15] and p-y curves by Reese and Welch [10] criterion, especially at the initial stage of loading.

\section{Discussion on the Critical Distance to Slope}

For laterally loaded piles, the maximum difference between piles near a slope and that in the horizontal ground is the lack of soil mass on the near-slope side. Thus, it cannot be regarded as a semi-infinite space, resulting in the reduction of the soil lateral resistance. However, it is complex to estimate the reduction effect accurately. Predictably, as the distance between the pile and the slope crest increases, the reduction effect gradually decreases until it disappears. To this end, scholars have made a significant effort to find the reasonable critical distance. When the distance is greater than the critical value, the influence of the slope can be ignored, and it can be treated as an ordinary laterally loaded pile in the horizontal ground so as to simplify the calculation. Taking load-displacement curve of the pile crest as the comparison standard, Poulos [6] proposed that the slope effect begins to reduce when the distance to the slope crest is greater than 4-5 times the pile diameter based on the small laboratory model test and numerical analysis, while 


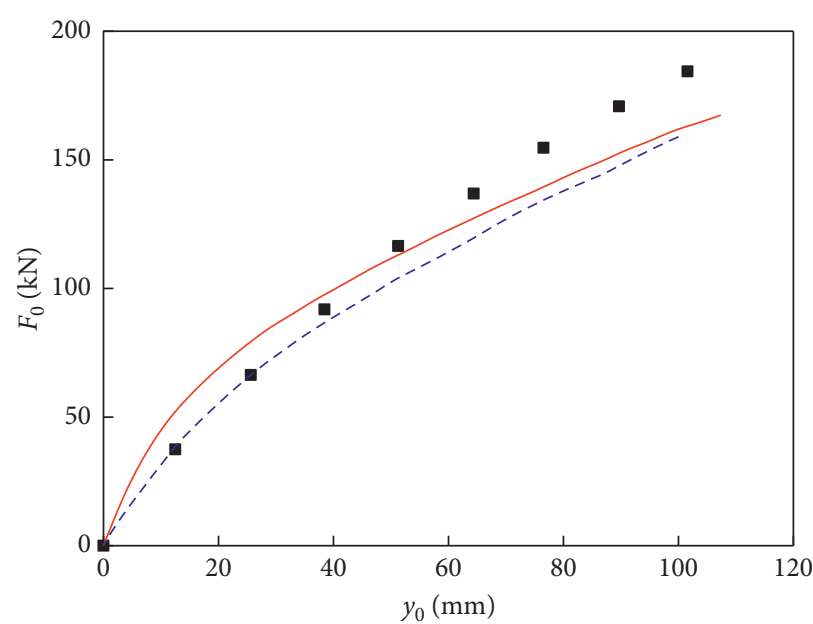

- Measured by Nimiyongskul $(b=0 D)$

- Simplified method $(b=0 D)$

- - Georgiadis and Georgiadis [16] $(b=0 D)$

(a)

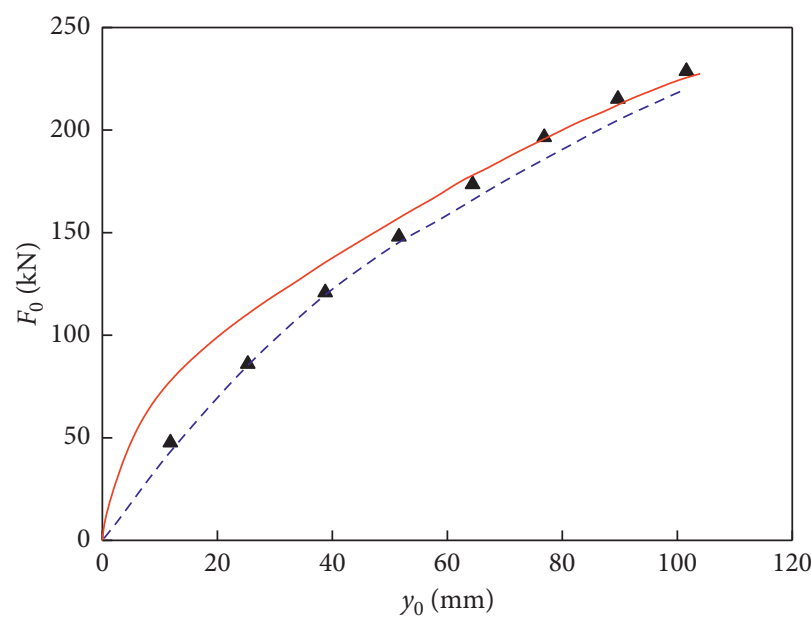

\ $\quad$ Measured by Nimiyongskul $(b=4 D)$ Simplified method $(b=4 D)$

- - Georgiadis and Georgiadis [16] $(b=4 D)$

(c)

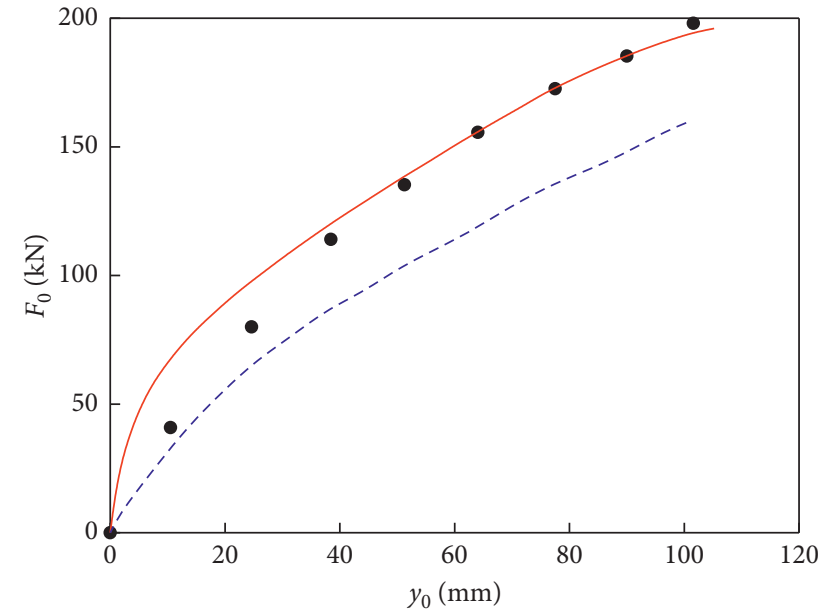

- Measured by Nimiyongskul $(b=2 D)$

Simplified method $(b=2 D)$

- - - Georgiadis and Georgiadis [16] $(b=2 D)$

(b)

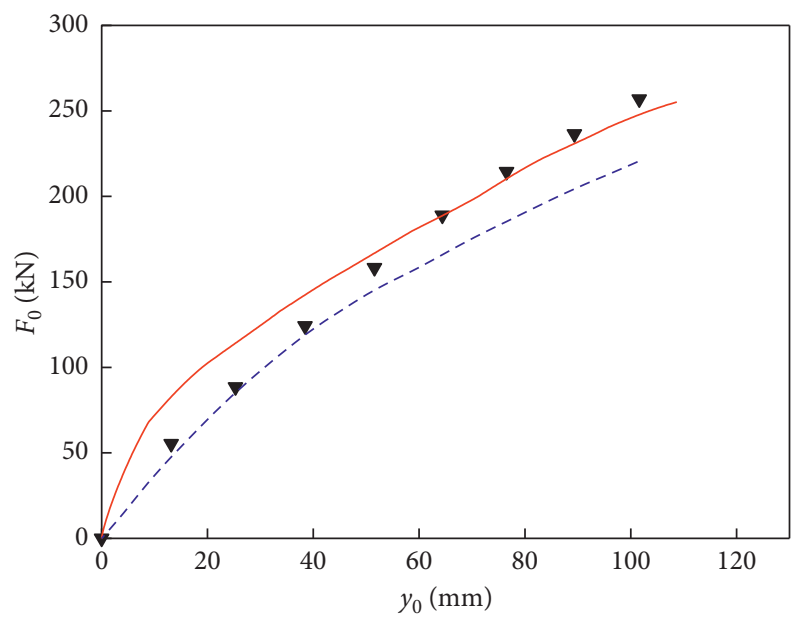

จ Measured by Nimiyongskul $(b=8 D)$

— Simplified method $(b=8 D)$

- - Georgiadis and Georgiadis [16] $(b=8 D)$

(d)

Figure 5: Comparison of lateral load $\left(F_{0}\right)$ versus displacement $\left(y_{0}\right)$ curves for different near-slope distances: (a) $b=0 D$; (b) $b=2 D$; (c) $b=4 D$; (d) $b=8 D$.

Nimityongskul et al. [18, 19] concluded that the slope effects are significantly reduced when the distance is 4 times the pile diameter and slope effect can be ignored after reaching a distance 8 times the pile diameter according to field test results. Taking the displacement comparison of the pile crest as a reference, Georgiadis and Georgiadis [16] believed that the weakening effect of the slope can be neglected when the distance from the pile center to the slope crest reached 6 times of the pile diameter in accordance with finite element analysis results.

For this case, it is also possible to analyze the difference in the ultimate soil resistance around the laterally loaded piles in the horizontal and sloping ground. Soil resistance around the pile with different distances to the slope is analyzed on the basis of the above derived equations. Basic parameters include $C_{\mathrm{u}}=50 \mathrm{kPa}, D=0.5 \mathrm{~m}, \gamma^{\prime}=18 \mathrm{kN} / \mathrm{m}^{3}$, and $\theta=45^{\circ}$. The distances to the slope crest are selected as $0 D, 2 D, 4 D, 6 D$, and $\infty$ (in the horizontal ground) for comparative analysis of $p_{\mathrm{u}}-z$ curves, as shown in Figures $8(\mathrm{a})-8(\mathrm{~d})$.

$p_{\text {hu }}$ represents the unit ultimate soil resistance around the laterally loaded pile installed in the horizontal ground, and $p_{\mathrm{su}}$ represents that around the laterally loaded pile in sloping ground. As can be seen from Figures $8(\mathrm{a})-8(\mathrm{~d}), p_{\mathrm{hu}}$ and $p_{\mathrm{su}}$ both increase with the increasing depth until reaching a constant value, which are only related to undrain shear strength $C_{\mathrm{u}}$ and the pile diameter $D$. However, the depth to reach such a contant value is significantly different, and there is $z_{\mathrm{sr}}>z_{\mathrm{r}}\left(z_{\mathrm{r}}\right.$ for piles in the horizontal ground and $z_{\mathrm{sr}}$ for piles near a slope). With the increase of near-slope distance, $z_{\mathrm{sr}}$ and 


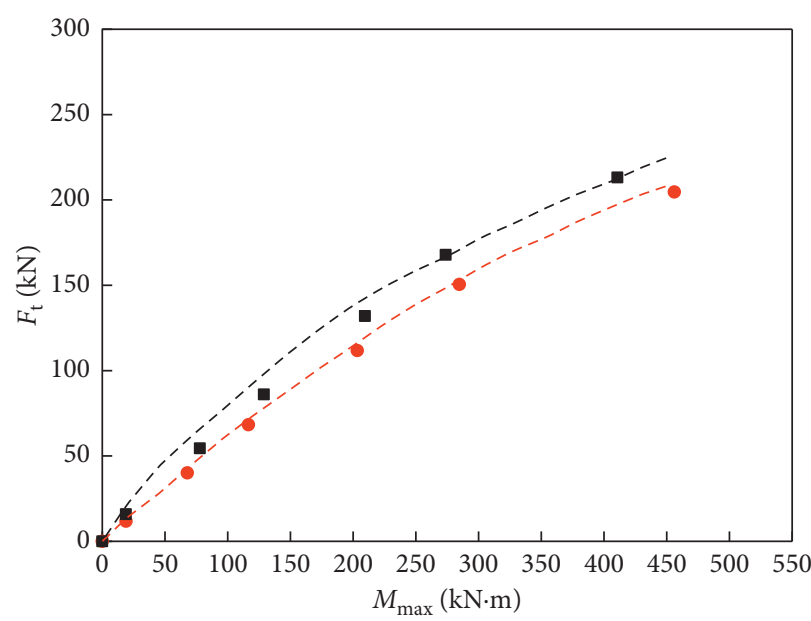

- Measured by Nimiyongskul $(b=0 D)$

- Measured by Nimiyongskul $(b=2 D)$

- - Simplified method $(b=0 D)$

- - S Simplified method $(b=2 D)$

(a)

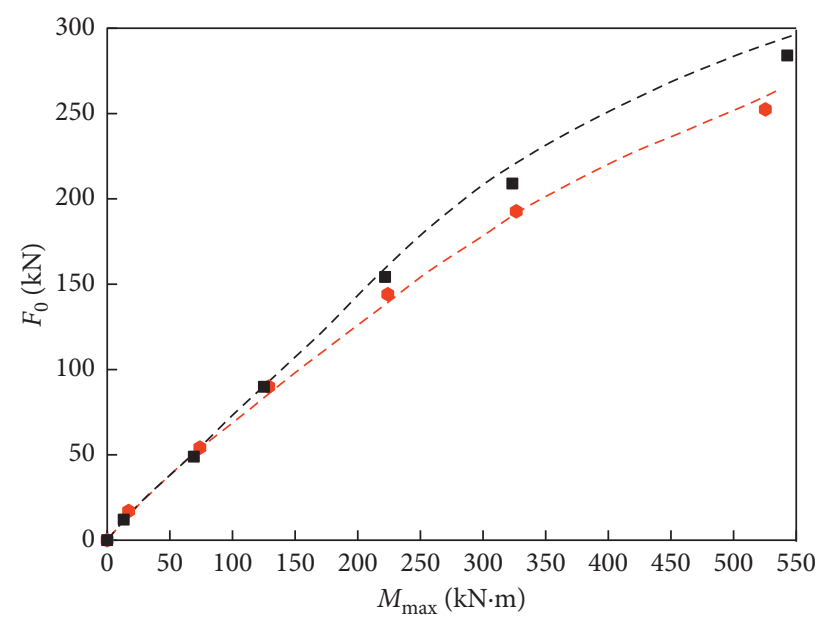

- Measured by Nimiyongskul $(b=4 D)$

- Measured by Nimiyongskul $(b=8 D)$

- - Simplified method $(b=4 D)$

- - Simplified method $(b=8 D)$

(b)

FiguRE 6: Comparison of lateral load $\left(F_{0}\right)$ versus maximum bending moment $\left(M_{\max }\right)$ curves for different near-slope distances: $(\mathrm{a}) b=0 D$ and $2 D$; (b) $b=4 D$ and $8 D$.

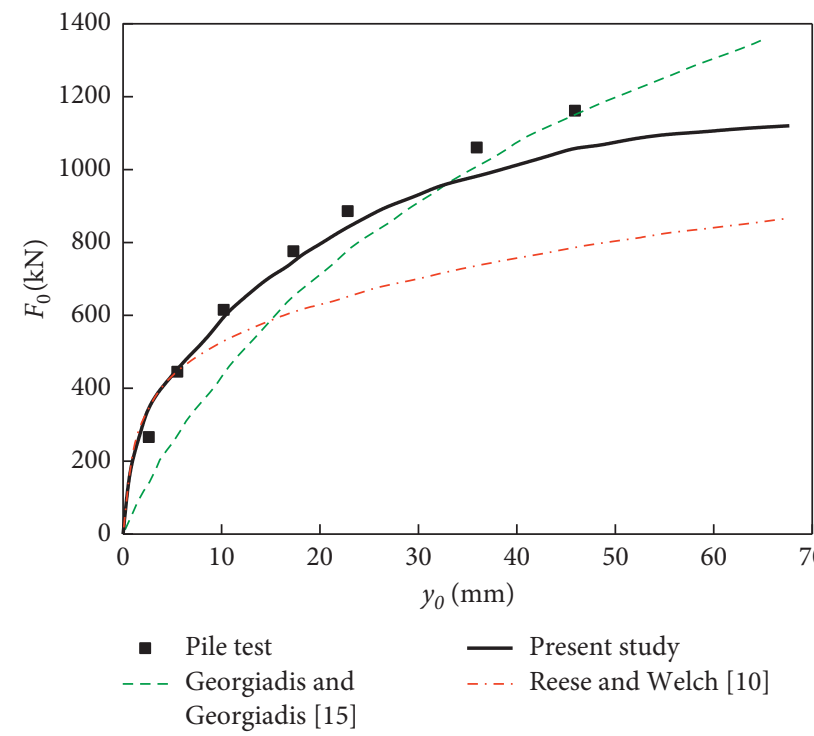

Figure 7: Comparison of lateral load $\left(F_{0}\right)$ versus displacement $\left(y_{0}\right)$ curves among model tests and theoretical studies.

$z_{\mathrm{r}}$ tend to intersect. In addition, there is a certain depth coincidence zone between $p_{\text {hu }}$ and $p_{\text {su }}$ below the ground. In this depth (denoted as $z_{\mathrm{c}}$ ), these values are identical. This trend is consistent with the finite element analysis results of Georgiadis and Georgiadis [16], and the reason for that is the plastic zone of soil wedge develops horizontally and vertically, respectively. The development area of the wedge does not reach the slope with a smaller load; thus, the slope above the depth (denoted as $z_{\mathrm{c}}$ ) does not affect the $p_{\mathrm{u}}$. When the plastic zone of the wedge extends to the slope surface, the slope begins to affect the lateral ultimate soil resistance per unit around the pile at the depth, resulting in the $p_{\mathrm{su}}<p_{\text {hu }}$ below $z_{\mathrm{c}}$.
It can be seen that the differences of unit ultimate soil resistances only exist within a certain range $\left(z_{\mathrm{c}}<z<z_{\mathrm{sr}}\right)$. Obviously, with the increase of near-slope distance $b$, the size of the weakened area gradually decreases, namely, the difference between $z_{\mathrm{c}}$ and $z_{\mathrm{sr}}$ is getting smaller and smaller. Until the critical near-slope distance is reached, $p_{\mathrm{hu}}$ and $p_{\mathrm{su}}$ are identical, in which $z_{\mathrm{c}}=z_{\mathrm{sr}}=z_{\mathrm{r}}$. Therefore, the near-slope distance in this case is defined as the critical near-slope distance $b_{\mathrm{cr}}$. When the near-slope distance of the pile is greater than $b_{\mathrm{cr}}$, the weakening effect of the slope on the loading capacity of the laterally loaded pile can be ignored. The key to considering the slope effect is the determination of $z_{\mathrm{c}}$ and $z_{\mathrm{r}}$.

As the mentioned earlier, $z_{\mathrm{r}}$ is the maximum expansion depth of the passive soil wedge, and the angle between the failure fracture surface and the pile is $45^{\circ}$. Therefore, as shown in Figure 9, the critical near-slope distance is the distance from the pile to slope crest when the maximum expansion depth of the soil wedge extends to slope crest. Since the failure angle of the passive soil wedge $\beta$ is $45^{\circ}$, when the near-slope distance reaches $b_{\mathrm{cr}}$, the failure surface just passes over the slope crest. While for the maximum expansion depth, only one expression is used to express the ultimate soil resistance around the pile. In the equation (11), if $p_{\mathrm{u} 1}=p_{\mathrm{u} 2}$, the expression of the critical near-slope distance can be obtained:

$$
b_{\mathrm{cr}}=z_{\mathrm{r}}=\frac{6 C_{\mathrm{u}} D}{\gamma^{\prime} D+J C_{\mathrm{u}}} .
$$

From the equation above, the critical near-slope distance is related to soil parameters and pile diameter. However, 4 times, 6 times, and 8 times of the pile diameter proposed by studies $[6,16,19]$ are all aimed at the certain critical nearslope distance, and the influence of soil parameters is not 


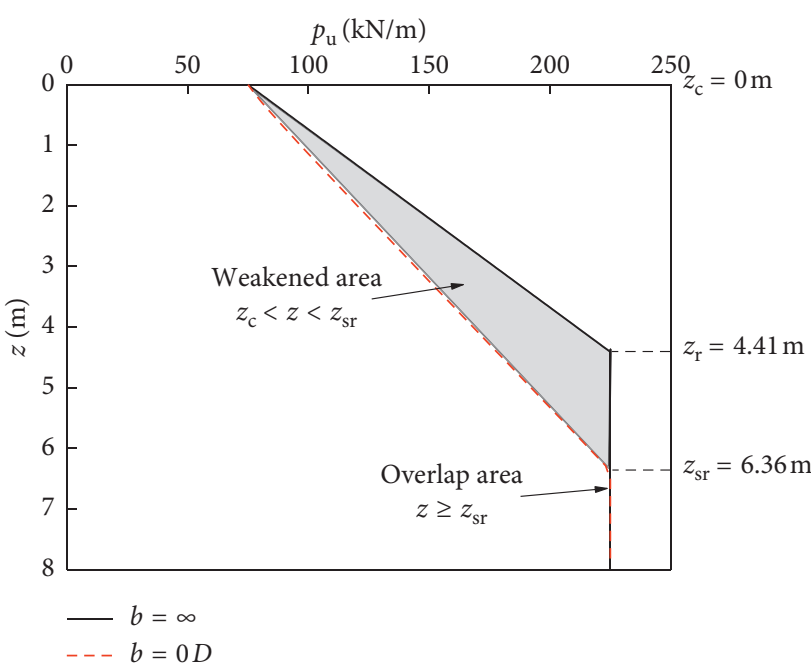

(a)

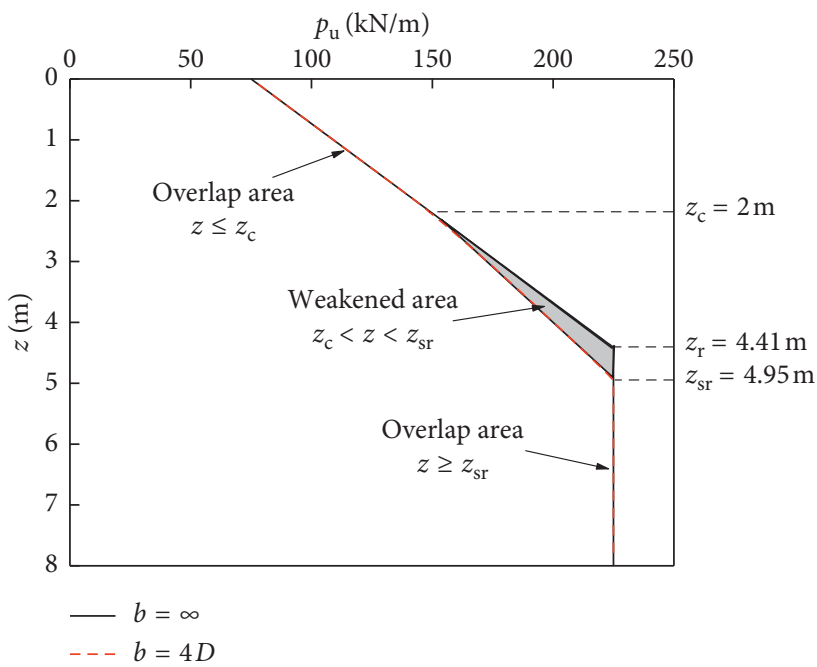

(c)

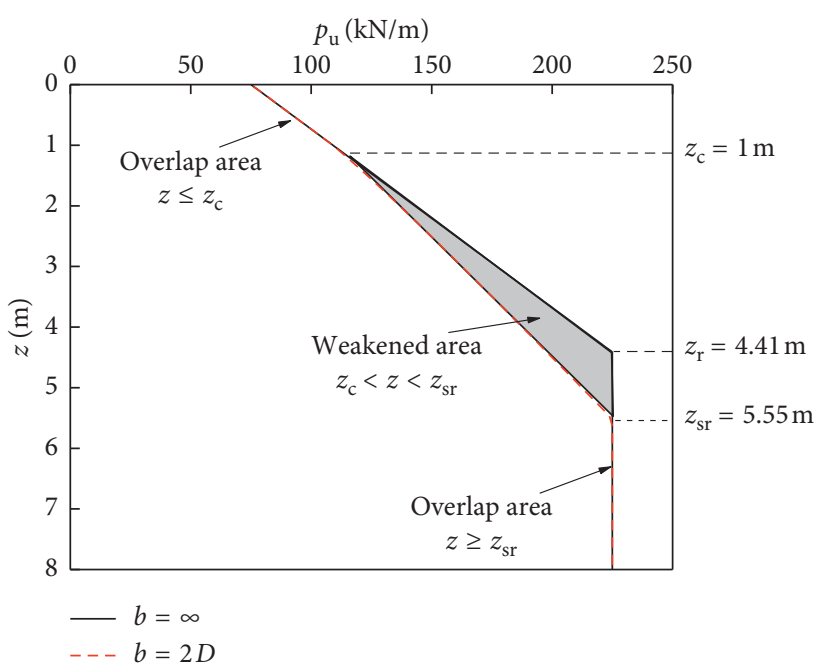

(b)

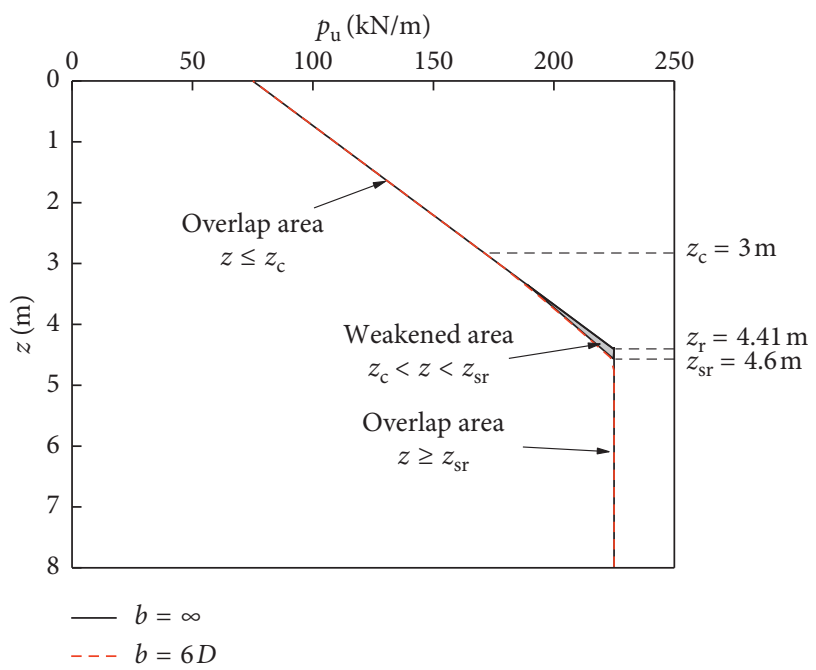

(d)

Figure 8: Comparison of limited resistance of soil with different depth along the pile: (a) $b=0 D$; (b) $b=2 D$; (c) $b=4 D$; (d) $b=6 D$.

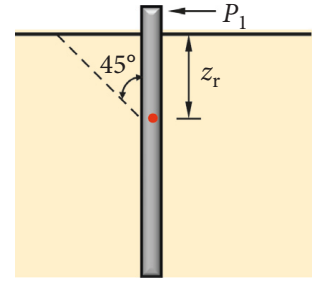

(a)

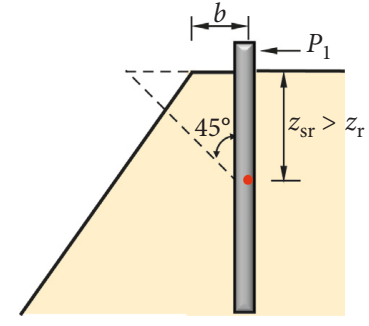

(b)

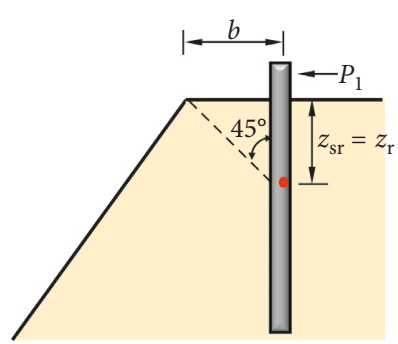

(c)

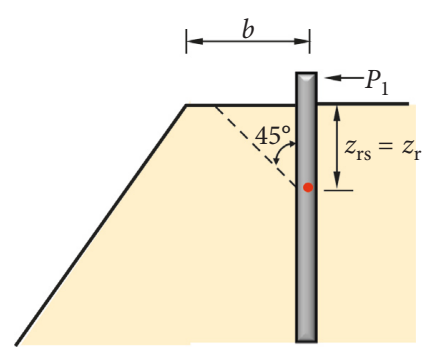

(d)

FigURE 9: The failure wedge of soil around pile with different distance from pile center to slope: (a) $b=\infty$; (b) $b<b_{\text {cr; }}$ (c) $b=b_{\text {cr }}$ (d) $b>b_{\text {cr. }}$.

considered. Therefore, the near-slope distance $b$ and the maximum depth $z_{\text {sr }}$ of soil wedges of the laterally loaded piles near a slope are divided by the pile diameter $D$ for dimensionless. $C_{\mathrm{u}}$ and $\theta$ are changed, and $z_{\mathrm{sr}} / D-b / D$ curves are analyzed.
As shown in Figures 10 and $11, z_{\mathrm{sr}} / D$ increases nonlinearly with the increase of $b / D$ and eventually tends to a constant of $b_{\mathrm{cr}}$. With the increase of the soil undrained shear strength, the critical near-slope distance $b_{\mathrm{cr}}$ increases, $C_{\mathrm{u}}$ increases from $50 \mathrm{kPa}$ to $150 \mathrm{kPa}$, and the critical near-slope 


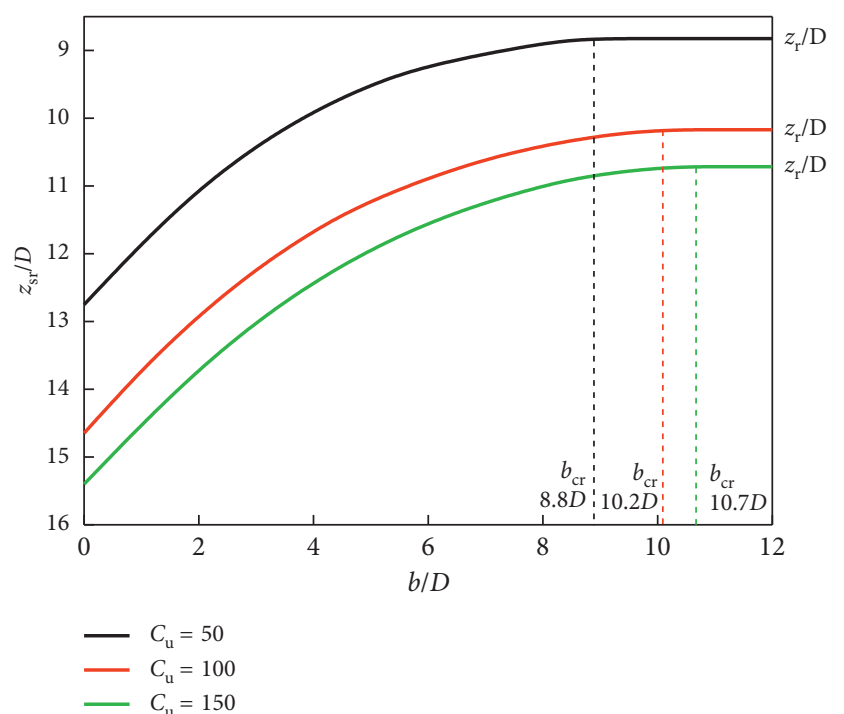

FIgUre 10: The relationship between $z_{\mathrm{sr}} / D$ and the undrained shear strength of soil $\left(\theta=45^{\circ}\right)$.

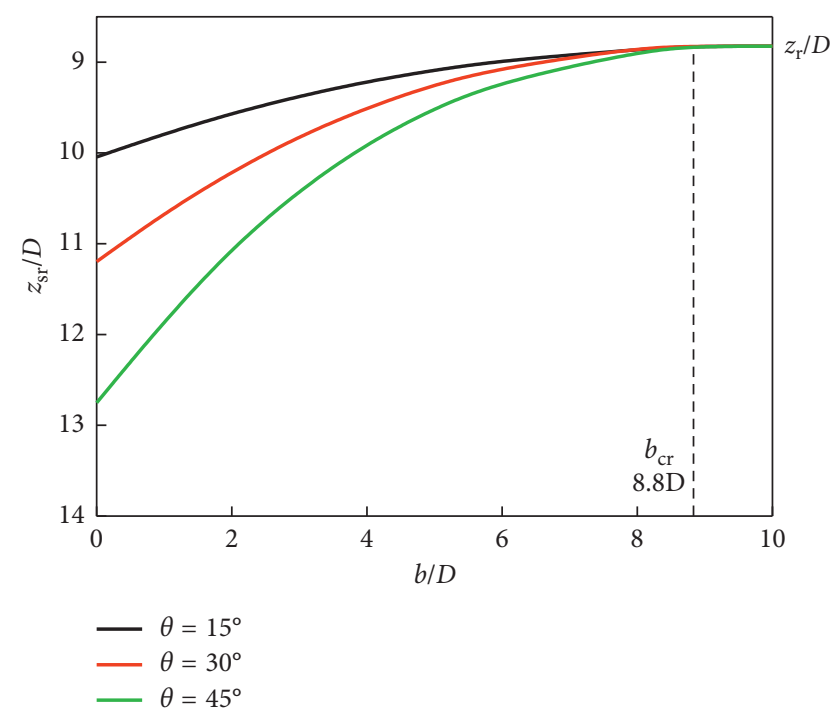

FIgURE 11: The relationship between $z_{\mathrm{sr}} / D$ and the angle of slope $\theta$ $\left(C_{\mathrm{u}}=50 \mathrm{kPa}\right)$.

distance increases from 8.8 times to 10.7 times the pile diameter. Through the analysis of Figure 11, changing the angle of the near-slope laterally loaded pile cannot affect the critical near-slope distance $b_{\mathrm{r}}$. From the proposed analysis on failure models of near-slope piles, the existence of slope mainly affects the wedge expansion of the soil wedge. With the increase of the near-slope distance, the slope does not have any effect on the loading process of the pile when the maximum developing wedge (which may be considered as ultimate loading) is not intersected with the slope. Obviously, the larger the $C_{\mathrm{u}}$, the larger the size of the maximum development wedge. Furthermore, the failure surface will not intersect with the slope with the increase of the nearslope distance $b_{\mathrm{cr}}$, and $b_{\mathrm{cr}}$ is not affected by the slope angle because the size of the largest wedge is independent of the slope angle.

\section{Conclusion}

In this paper, by using the modified $\mathrm{p}-\mathrm{y}$ curve, a passive wedge failure model of the soil around the laterally loaded piles near a slope is proposed. The model can fully consider the influence of the slope shape, pile position, and soil characteristics; the equivalent expansion depth of the soil wedge failure is proposed with the comparison of that in the horizontal ground. Based on the passive soil wedge failure model, the calculation method of p-y curve for near-slope horizontal loading piles is proposed. The results show that calculated values from this presented method are in good agreement with measured data. Furthermore, based on the distribution law of the lateral ultimate soil resistance, the critical near-slope distance is defined, whose expression is derived, and the influence of the near-slope distance on the pile is deeply discussed. The main conclusions are as follows:

(1) The calculation shows that the critical near-slope distance is related to the soil shear strength. When the distance between the pile and the slope is greater than that of the critical value, the slope-weakening effect on the horizontal loading capacity of the pile can be ignored.

(2) The slope will reduce the values of $p_{u}$ in a certain area below the ground. When the pile is placed near-slope crest (i.e., $b=0$ ), the area of $p_{\mathrm{u}}$ values from the ground to the maximum depth of the failure wedge are completely weakened. As the slope distance increases, the weakened area will gradually become smaller until the critical slope distance is reached, the weakened area no longer exists, and the $p_{\mathrm{u}}-z$ curves of soil around pile near-slope crest and that of soil around pile in the ground are coincide.

(3) The critical near-slope distance is increasing with the increase of the undrained strength while independent of the slope angle.

\section{Data Availability}

The data used to support the findings of this study are included within the article.

\section{Conflicts of Interest}

The authors declare that there are no conflicts of interest.

\section{Acknowledgments}

The authors would like to acknowledge the financial support from the National Science Foundation of China under contract number 51678230 .

\section{References}

[1] S. M. Springman, "Lateral loading on piles due to simulated embankment construction," Ph.D Thesis, University of Cambridge, Cambridge, UK, 1989.

[2] C. Viggiani, "Ultimate lateral load on piles used to stabilise landslide," in Proceedings of the 10th International Conference 
on Soil Mechanics and Foundation Engineering, Stockholm, Sweden, June 1981.

[3] H. G. Poulos, "Design of reinforcing piles to increase slope stability," Canadian Geotechnical Journal, vol. 32, no. 5, pp. 808-818, 1995.

[4] C. F. Leung, Y. K. Chow, and R. F. Shen, "Behavior of pile subject to excavation-induced soil movement," Journal of Geotechnical and Geoenvironmental Engineering, vol. 126, no. 11, pp. 947-954, 2000.

[5] C. K. Choy, J. R. Standing, and R. J. Mair, "Stability of a loaded pile adjacent to a slurry-supported trench," Géotechnique, vol. 57, no. 10 , pp. 807-819, 2007.

[6] H. G. Poulos, "Behavior of laterally loaded piles near a cut or slope," Australian Geomechanics Journal, vol. 6, no. 1, pp. 6-12, 1976.

[7] C. Jiang, Y. Li, L. Liu, and H. Lin, "Nonlinear analysis of flexible pile near undrained clay slope under lateral loading," Advances in Civil Engineering, vol. 2018, Article ID 6817362, 13 pages, 2018.

[8] P. Yin, W. He, and Z. J. Yang, "A simplified nonlinear method for a laterally loaded pile in sloping ground," Advances in Civil Engineering, vol. 2018, Article ID 5438618, 9 pages, 2018.

[9] H. Matlock, "Correlations for design of laterally loaded piles in soft clay," in Proceedings of the Second Annual Offshore Technology Conference, Paper No. OTC 1204, pp. 577-594, Houston, TX, USA, April 1970.

[10] L. C. Reese and R. C. Welch, "Lateral loading of deep foundations in stiff clay," Journal of Geotechnical Engineering Division, vol. 101, no. 7, pp. 633-649, 1975.

[11] J. Kodikara, A. Haque, and K. Y. Lee, “Theoretical $p-y$ curves for laterally loaded single piles in undrained clay using bezier curves," Journal of Geotechnical and Geoenvironmental Engineering, vol. 136, no. 1, pp. 265-268, 2010.

[12] Y. Kim, S. Jeong, and S. Lee, "Wedge failure analysis of soil resistance on laterally loaded piles in clay," Journal of Geotechnical and Geoenvironmental Engineering, vol. 137, no. 7, pp. 678-694, 2011.

[13] K. S. Chae, K. Ugai, and A. Wakai, "Lateral resistance of short single piles and pile groups located near slopes," International Journal of Geomechanics, vol. 4, no. 2, pp. 93-103, 2004.

[14] K. Muthukkumaran, R. Sundaravadivelu, and S. R. Gandhi, "Effect of slope on $p-y$ curves due to surcharge load," Soils and Foundations, vol. 48, no. 3, pp. 353-361, 2008.

[15] K. Georgiadis and M. Georgiadis, "Undrained lateral pile response in sloping ground," Journal of Geotechnical and Geoenvironmental Engineering, vol. 136, no. 11, pp. 1489-1500, 2010.

[16] K. Georgiadis and M. Georgiadis, "Development of p-y curves for undrained response of piles near slopes," Computers and Geotechnics, vol. 40, no. 1, pp. 53-61, 2012.

[17] K. Muthukkumaran, "Effect of slope and loading direction on laterally loaded piles in cohesionless soil," International Journal of Geomechanics, vol. 14, no. 1, pp. 1-7, 2014.

[18] N. Nimityongskul and S. Ashford, "Effect of soil slope on lateral capacity of piles in cohesive soils,"in Proceedings of the 9th US National and 10th Canadian Conference on Earthquake Engineering, Paper No 366, Toronto, Canada, July 2010.

[19] N. Nimityongskul and Y. Kawamata, D. Rayamajhi, S. A. Ashford, Full-scale tests on effects of slope on lateral capacity of piles installed in cohesive soils," Journal of Geotechnical and Geoenvironmental Engineering, vol. 144, no. 1, article 04017103, 2018.

[20] D. Rathod, K. Muthukkumaran, and T. G. Sitharam, "Effect of slope on $p-y$ curves for laterally loaded piles in soft clay,"
Geotechnical and Geological Engineering, vol. 36, no. 3, pp. 1509-1524, 2018.

[21] J. D. Murff and J. M. Hamilton, " $P$-ultimate for undrained analysis of laterally loaded piles," Journal of Geotechnical Engineering, vol. 119, no. 1, pp. 91-107, 1993.

[22] L. C. Reese, W. M. Isenhower, and S. T. Wang, Analysis of Design of Shallow and Deep Foundations, John Wiley \& Sons, Hoboken, NJ, USA, 2006.

[23] C. Lin, J. Han, C. Bennett, and R. L. Parsons, "Analysis of laterally loaded piles in sand considering scour hole dimensions," Journal of Geotechnical and Geoenvironmental Engineering, vol. 140, no. 6, article 04014024, 2014.

[24] C. Lin, J. Han, C. Bennett, and R. L. Parsons, "Analysis of laterally loaded piles in soft clay considering scour-hole dimensions," Ocean Engineering, vol. 111, pp. 461-470, 2016.

[25] M. W. O’Neil and S. M. Gazioglu, "An evaluation of p-y relationships in clays," Rep. PRAC 82-41-2, American Petroleum Institute, University of Houston, Houston, TX, USA, 1984.

[26] D. P. Stewart, "Reduction of undrained lateral pile capacity in clay due to an adjacent slope," Australian Geomechanics, vol. 34, no. 4, pp. 17-23, 1999.

[27] Y. Wu, X. Zhou, Y. Gao, L. Zhang, and J. Yang, "Effect of soil variability on bearing capacity accounting for non-stationary characteristics of undrained shear strength," Computers and Geotechnics, vol. 110, pp. 199-210, 2019.

[28] J. Ji, C. Zhang, Y. Gao, and J. Kodikara, "Effect of 2D spatial variability on slope reliability: a simplified FORM analysis," Geoscience Frontiers, vol. 9, no. 6, pp. 1631-1638, 2018.

[29] J. Ji, C. Zhang, Y. Gao, and J. Kodikara, "Reliability-based design for geotechnical engineering: an inverse FORM approach for practice," Computers and Geotechnics, vol. 111, pp. 22-29, 2019.

[30] D. A. Brown and C.-F. Shie, "Some numerical experiments with a three dimensional finite element model of a laterally loaded pile," Computers and Geotechnics, vol. 12, no. 2, pp. 149-162, 1991.

[31] K. Bhushan, S. C. Haley, and P. T. Fong, "Lateral load tests on drilled piers in stiff clays," Journal of Geotechnical Engineering Division, vol. 105, no. 8, pp. 969-985, 1979. 


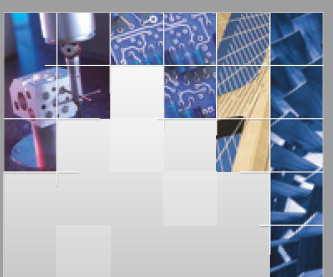

\section{Enfincering}
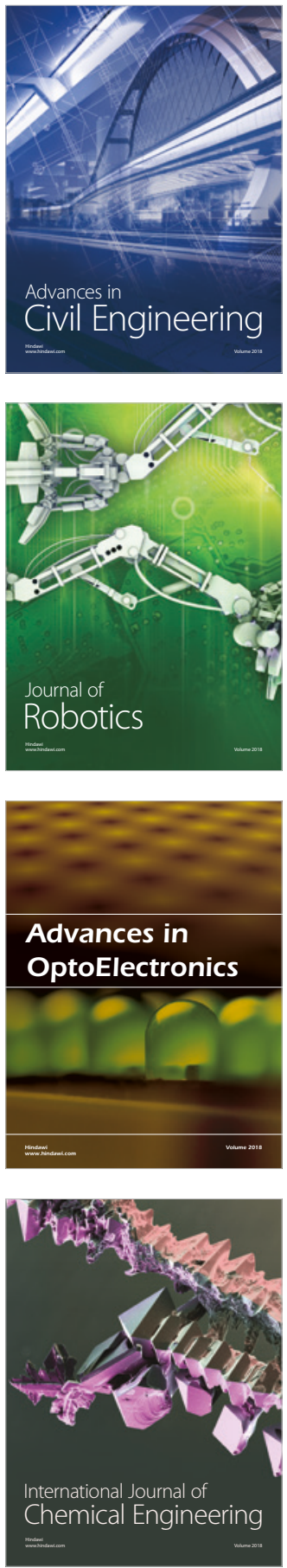

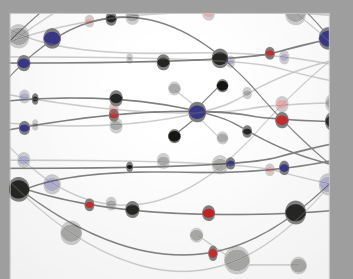

\section{Rotating \\ Machinery}

The Scientific World Journal

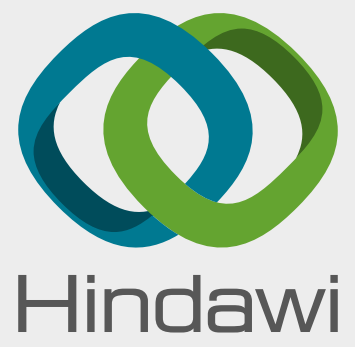

Submit your manuscripts at

www.hindawi.com
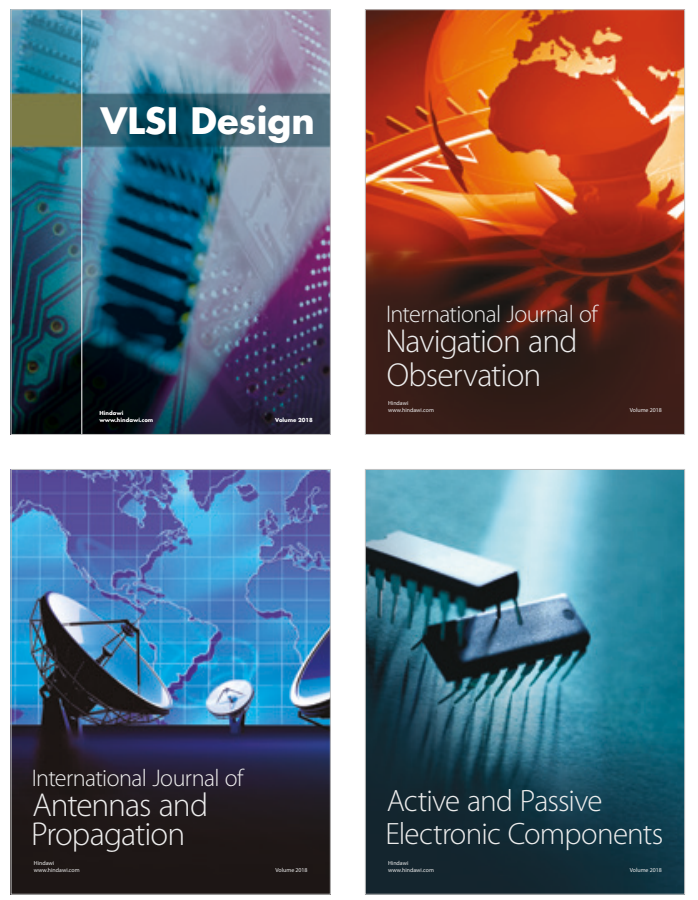
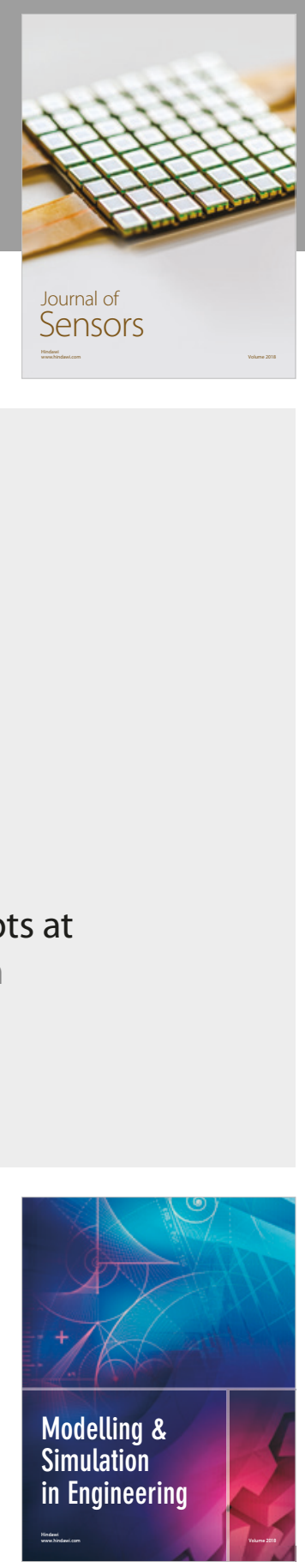

\section{Advances \\ Multimedia}
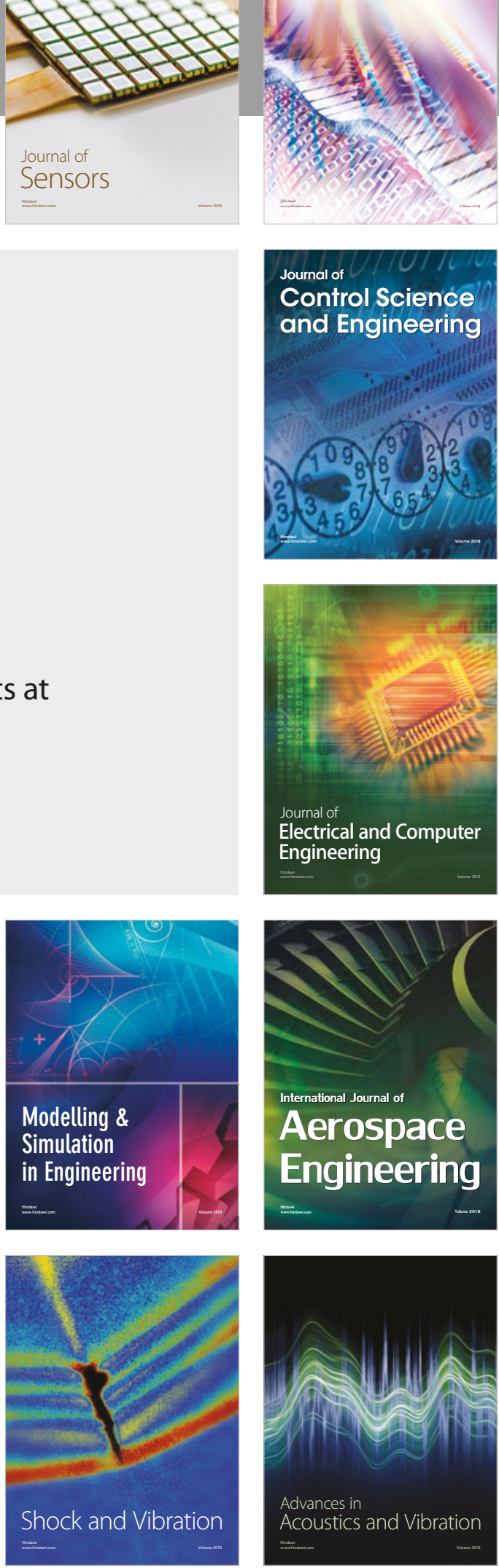